\title{
ANTIOXIDANT, ANTI-INFLAMMATORY, AND ANTIDIABETIC ACTIVITY OF HYDROALCOHOLIC EXTRACT OF OCIMUM SANCTUM: AN IN-VITRO AND IN-SILICO STUDY
}

\author{
VINEET MEHTA, ARUN SHARMA, PALLAVI KAILKHURA, UDAYABANU MALAIRAMAN*
}

Department of Pharmacy, Jaypee University of Information Technology, Waknaghat - 173 234, Himachal Pradesh, India.

Email: m_udayabanu@rediffmail.com

Received: 10 May 2016, Revised and Accepted: 21 May 2016

\section{ABSTRACT}

Objective: Ocimum sanctum is known to be beneficial in the management of diabetes, however, its mechanism remains unexplored. This study was aimed to gain insite into the mechanisms through which it may counter diabetes and its complications.

Methods: Hydroalcoholic whole plant extract of 0 . sanctum was screened for its antidiabetic potential and ability to counter oxidative and inflammatory stress through various in-vitro assays. Further, bioactive compounds that may be responsible for its antidiabetic activity were predicted through molecular-docking studies.

Results: Crude extractive yield of $35.43 \%$ was obtained from Soxhlet extraction which mainly showed the presence of flavonoids, alkaloids, glycosides, and saponins. Plant extract showed good potential to scavenge 2,2-diphenyl-1-picrylhydrazyl free radical (40.95-68.71\%) which may be attributed to its high phenolic $(0.366 \mathrm{mg}$ gallic acid equivalent/g) and flavonoid $(0.113 \mathrm{mg}$ quercetin equivalent/g) contents. Plant showed exceptional antiinflammatory activity which was evaluated through inhibition of protein denaturation (47.61-82.37\%) and red blood cell membrane stabilization assay (43.66-78.28\%). Further, extract treatment greatly inhibited $\alpha$-glucosidase enzyme (34.17-71.45\%) but failed to produce noticeable inhibition of $\alpha$-amylase activity (1.94-14.88\%). Docking studies predicted that rosmarinic acid, stigmasterol, linalool, bieugenol, and aesculin may be responsible for antidiabetic activity possessed by the plant through their interaction with the insulin receptor

Conclusion: These findings conclude that $O$. sanctum may be beneficial in managing diabetes and its associated complications through inhibiting $\alpha$-glucosidase activity, reducing oxidative and inflammatory stress.

Keywords: Diabetes mellitus, Ocimum sanctum, Antioxidant, Anti-inflammatory, Docking, Diabetic complications

(C) 2016 The Authors. Published by Innovare Academic Sciences Pvt Ltd. This is an open access article under the CC BY license (http://creativecommons org/licenses/by/4. 0/) DOI: http://dx.doi.org/10.22159/ajpcr.2016.v9i5.12713

\section{INTRODUCTION}

Rapid socioeconomic development in last decades has shown rapid rise in the lifestyle disorders among which diabetes mellitus (DM) is growing rapidly and has become epidemic in many parts of the world. In 2015, DM and its associated complications affected 415 million people globally and resulted in 5 million deaths [1]. Regardless of the rapid and continues advancing health-care technology, it is predicted that DM cases will rise 642 million by the year 2040 [1]. DM is generally associated with several other complications, among which neuropathy, nephropathy, cardiovascular complications, and retinopathy are most pronounced and are predominantly accountable for the morbidity and mortality associated with DM [2]. During DM, excessive glucose is available for metabolism through hexosamine, protein kinase-C, poly (adenosine diphosphate-ribose) polymerase, and nitric oxide pathways which generates a high level of reactive oxygen and nitrogen species. Excessive free radicals saturate antioxidant enzymes of our body, viz., catalase, glutathione, and superoxide dismutase and interact with different cellular biomolecules, compromising their normal function and physiology, which results in various diabetic complications [3] Diabetic complications are further extravagated by persistent inflammatory stress which is inflicted as a result of hyperglycemiainduced chronic elevation in pro-inflammatory molecules such as cytokines and chemokines [4]. Further, interplay between inflammatory and oxidative stress is known to play an important part in the development of insulin resistance [5]. These complications and morbidity associated with diabetes are reported even after continuous treatment with commercially available drugs which act primarily by disposing excessive glucose from the blood [6], therefore, providing only temporary and symptomatic relief from DM. These medications have to be taken throughout the life besides having several side effects. Therefore, need of the day is to boost up search for certain alternative therapeutic strategies or novel molecules that can not only prevent diabetes and associated complications but also reverse the damage already done.

Nature has provided us with a variety of plants which have been used by human civilization for the prevention and cure of several ailments since time immemorial. A rich heritage of this traditional medicinal knowledge of nature can be reflected form the ancient scholastic work illustrated in the ancient texts such as Atharvaveda (Indian sacred text) and Ayurveda (Indian traditional system of medicine) [7]. Ocimum sanctum $\mathrm{L}$. (Tulsi) is an ethnomedicinal herb found throughout Indian subcontinent which is consumed as a part of food and have been traditionally used for thousands of years for the treatment of ailments such as cancer, diabetes, fungal and microbial infection, cardiovascular disorders, bronchitis, bronchial asthma, malaria, diarrhea, dysentery, skin diseases, and arthritis [8], but identification of bioactive components and their role in particular ailment is yet to done. It has been used traditionally for the management of diabetes $[9,10]$ and various experimentation conducted in diabetic rodents demonstrates that different extracts of $O$. sanctum reduce blood glucose level [11-14], stimulate insulin secretion from pancreas [15], restore normal lipid profile $[14,16]$, and help in the management of diabetic complications [17]. None of the experimental work fully demonstrates the mechanism which is exploited by 0 . sanctum to manage diabetes and associated complications. Further, not much work has been focused to identify exactly which constituent/s present in this plant aids in benefiting diabetic condition. Looking on the traditional medicinal value of this plant and continuously increasing demand for better treatment strategies and novel antidiabetic molecules, this plant may prove to be useful in the management of diabetes and its associated complications. Further, docking screening of various constituents present in this plant 
on antidiabetic targets may provide us with new novel antidiabetic molecule/s which can be screened further as potential antidiabetics.

The aim of this study was to gain preliminary insite into the mechanism through which it can aid in controlling diabetes and its complications through in-vitro and in-silico tools. We evaluated the potential of hydroalcoholic extract of $O$. sanctum (HEOS) to neutralize oxidative and inflammatory stress which plays a decisive role in the development and progression of diabetic complications. Further, potential antidiabetic mechanism of this plant was experimentally demonstrated through in-vitro assays and bioactive constituents which may be responsible for its antidiabetic property were predicted from in-silico docking studies.

\section{MATERIALS AND METHODS}

\section{Materials}

All the chemicals used in this study were procured from Sigma-Aldrich, Loba Chemie, Merck, SD Fine-Chem, Himedia, and Spectrochem.

\section{Plant collection, extraction, and phytochemical screening}

Whole plant of $O$. sanctum (RHD 238) was procured from Natural Remedies, Bengaluru, India. $100 \mathrm{~g}$ dried leaves were subjected to hydroalcoholic (ethanol: water; 30:70) extraction using Soxhlet apparatus at the temperature of $60^{\circ} \mathrm{C}$ for $72 \mathrm{hrs}$. The extract was filtered while hot, concentrated to semisolid mass under reduced pressure using rotary evaporator (Heidolph 4011, USA) and lyophilized to obtain completely dry power. Powdered extract was stored at $4^{\circ} \mathrm{C}$ until used further. HEOS was then subjected to the preliminary phytochemical screening as per the previously defined and widely used methods [18].

\section{In-vitro evaluation of antioxidant activity Determination of total phenolic content}

Total phenolic content of the HEOS was determined using a simple, rapid, widely used, and well-established model using Folin-Ciocalteu reagent as described previously [19]. Briefly, reaction mixture was prepared by mixing together $40 \mathrm{ml}$ acetone, $40 \mathrm{ml}$ methanol, $20 \mathrm{ml}$ water, and $0.1 \mathrm{ml}$ acetic acid. $200 \mathrm{mg} / \mathrm{ml}$ concentration of extract was prepared in double distilled water and vortexed with equal volume of the prepared reagent till extract get completely solubilized. Reaction mixture was then incubated over water bath at $60^{\circ} \mathrm{C}$ for $1 \mathrm{hrs}$ followed by cooling under tap water. $400 \mu \mathrm{L}$ of this reaction mixture was transferred to the test tube having $1.6 \mathrm{ml}$ sodium carbonate $(7.5 \%)$ and $2 \mathrm{ml}$ of Folin-Ciocalteu reagent $(0.1 \%)$. All the samples were then incubated in dark at room temperature for $1 \mathrm{hrs}$, and absorbance was recorded at $525 \mathrm{~nm}$ using a UV spectrophotometer (Go Scan Microplate Reader, Thermo Scientific, USA). Entire procedure was performed in triplicate. Standard curve of gallic acid was prepared spectrophotometrically using the same procedure. Total phenolic content present in the HEOS was expressed in mg gallic acid equivalent (GAE)/g dried extract using the linear regression equation obtained from the standard curve of gallic acid.

\section{Determination of total flavonoid content}

Total flavonoids present in the extract were determined using simple and previously well-established spectrophotometric method [20] by taking quercetin as a standard compound. $0.5 \mathrm{ml}$ of $200 \mathrm{mg} / \mathrm{ml}$ extract was transferred to the test tube containing $75 \mu \mathrm{L}$ of $5 \% \mathrm{NaNO}_{2}$ solution. Mixture was allowed to stand for 10 minutes after which $150 \mu \mathrm{L}$ of a $10 \% \mathrm{AlCl}_{3} \cdot 6 \mathrm{H}_{2} \mathrm{O}$ solution was added to the reaction tube. A reaction mixture was allowed to stand for 5 more minutes after which $0.5 \mathrm{ml}$ $\mathrm{NaOH}(1 \mathrm{M})$ and $2.5 \mathrm{ml}$ of distilled water were added to it. Absorbance was then measured at $510 \mathrm{~nm}$ using the UV spectrophotometer. Entire procedure was performed in triplicate. Standard curve of quercetin was prepared using the same procedure. Total flavonoid content present in the HEOS was expressed as mg querctine equivalent $(\mathrm{QE}) / \mathrm{g}$ dried extract using the linear regression equation obtained from the standard curve of quercetin. 2,2-diphenyl-1-picrylhydrazyl (DPPH) radical scavenging activity DPPH radical scavenging was used to determine the free radical scavenging potential of the HEOS according to the previously defined method [21], with slight modifications. Briefly, $0.4 \mathrm{mM}$ solution of DPPH was prepared 95\% methanol. Different concentrations $(250-1000 \mu \mathrm{g} / \mathrm{ml})$ of extract and ascorbic acid (standard) were also prepared in $95 \%$ methanol and $10 \mathrm{ml}$ of sample was then transferred into the reaction test tubes. $3 \mathrm{ml}$ of DPPH solution was added to each tube and mixed vigorously followed by 30 minutes incubation in dark at $37^{\circ} \mathrm{C}$. For the purpose of control reaction, equivalent volume of $95 \%$ methanol in DPPH was used. Absorbance of all the samples was recorded in triplicate at $517 \mathrm{~nm}$ using the UV spectrophotometer. \% DPPH radical scavenging activity was calculated using following equation.

$$
\begin{aligned}
& \text { DPPH radical scavenging activity }(\%)= \\
& \left(\frac{\text { Absorbance of control }- \text { Absorbance of sample }}{\text { Absorbance of control }}\right) \times 100
\end{aligned}
$$

\section{In-vitro evaluation of anti-inflammatory activity Inhibition of protein denaturation}

Anti-inflammatory activity of the natural or synthetic samples has been widely screened by employing inhibition of protein denaturation model in recent past. In the present study, we evaluated the potential of HEOS to inhibit albumin denaturation in accordance with method previously described by Ullah et al. [22], with slight modifications. Reaction mixture consisted of $1 \mathrm{ml}$ of different concentrations of plant extract or diclofenac sodium $(250-1000 \mu \mathrm{g} / \mathrm{ml})$ or distilled water (blank) and $1 \mathrm{ml}$ of $1 \%$ aqueous bovine serum albumin prepared in phosphate buffered saline (PBS; pH 6.4). Reaction mixtures were then incubated at $37^{\circ} \mathrm{C}$ for 30 minutes followed by incubation at denaturing temperature of $57^{\circ} \mathrm{C}$ for 5 minutes. Each tube was cooled under running tap water, and the respective absorbance was recorded spectrophotometrically at $660 \mathrm{~nm}$. Entire experimentation was performed in triplicate and percent inhibition of protein denaturation was determined using the following equation.

$\%$ Inhibition of albumin denaturation $=1-\left(\frac{\text { Abstest }}{\text { Abscontrol }}\right) \times 100$

\section{Red blood cell (RBC) membrane stabilization assay}

Potential of the plant extract to stabilize cellular membrane of RBCs was evaluated according to protocol previously described by Asanuma et al., Sadique et al. and Shinde et al. [23-25]; with slight modification. Sufficient amount of goat blood was obtained from slaughterhouse in the glass tubes having $1.8 \mathrm{mg} / \mathrm{ml} \mathrm{5 \%}$ ethylenediaminetetraacetic acid solution and mixed gently. Blood was centrifuged at $5000 \mathrm{rpm}$ for 15 minutes and washed thrice with equal volumes of saline. Further, $10 \% \mathrm{v} / \mathrm{v}$ suspension of RBC was prepared in normal saline; which was stored at $4^{\circ} \mathrm{C}$ and used within $6 \mathrm{hrs}$ of preparation. Reaction mixture was prepared by mixing $1 \mathrm{ml}$ of $10 \%$ RBCs suspension and $1 \mathrm{ml}$ of different concentrations $(250-1000 \mu \mathrm{g} / \mathrm{ml})$ of HEOS, diclofenac sodium, or distilled water (blank) in the test tubes. All the samples were incubated at $57^{\circ} \mathrm{C}$ for 30 minutes over water bath and were immediately cooling under running tap water. Samples were centrifuged at $2500 \mathrm{rpm}$ for 5 minutes, and absorbance of the supernatant was measured spectrophotometrically at $560 \mathrm{~nm}$. Entire experimentation was performed in triplicate, and percent inhibition of RBC membrane was determined using the following equation.

$\%$ Membrane stabilization $=\left(\frac{\mathrm{Abs}_{\text {control }}-\mathrm{Abs}_{\text {sample }}}{\mathrm{Abs}_{\text {control }}}\right) \times 100$

\section{In-vitro evaluation of antidiabetic activity} Inhibition of $\alpha$-glucosidase activity

Method of Elya et al. [26] was used to determine the $\alpha$-glucosidase inhibitory activity of plant extract and acarbose was used as the standard drug. Briefly, reaction mixture consisted of $490 \mu \mathrm{L}$ phosphate 
buffer (pH 6.8), $250 \mu \mathrm{L}$ of $5 \mathrm{mM}$ p-nitrophenyl $\alpha$-D-glucopyranoside, and $10 \mu \mathrm{L}$ of different concentrations $(250-1000 \mu \mathrm{g} / \mathrm{ml})$ of plant extract, acarbose, or distilled water (blank). Reaction mixture was incubated at $37^{\circ} \mathrm{C}$ for 5 minutes, and then, $250 \mu \mathrm{L} \alpha$-glucosidase $(0.15$ unit $/ \mathrm{ml}$ ) was added to each tube and the tubes were then incubated at $37^{\circ} \mathrm{C}$ for 15 minutes. The reaction was terminated by the addition of $200 \mu \mathrm{L} \mathrm{Na} \mathrm{CO}_{3} 200 \mathrm{mM}$ ). $\alpha$-Glucosidase inhibitory activity of the HEOS and acarbose was determined spectrophotometrically at $400 \mathrm{~nm}$. Entire experimentation was performed in triplicate and percent inhibition of $\alpha$-glucosidase enzyme activity was determined using the following equation.

$\% \alpha-$ glucosidase inhibition $=\left(\frac{\mathrm{Abs}_{\text {control }}-\mathrm{Abs}_{\text {sample }}}{\mathrm{Abs}_{\text {control }}}\right) \times 100$

\section{Inhibition of $\alpha$-amylase activity}

We evaluated the potential of HEOS to inhibit $\alpha$-amylase enzymatic activity according to method previously described by Zengin et al. [27], with some modifications. Briefly, $30 \mu \mathrm{L}$ of different concentrations of plant extract $(250-1000 \mu \mathrm{g} / \mathrm{ml})$ were mixed with $60 \mu \mathrm{L}$ of $\alpha$-amylase (1 U/ml PBS; pH 6.9) in a 96-well microplate. Plate was incubated at $37^{\circ} \mathrm{C}$ for 10 minutes and the reaction was initiated by adding $60 \mu \mathrm{L}$ starch solution $(0.05 \% \mathrm{w} / \mathrm{v}$ in PBS; pH 6.9) to each well. Plate was then again incubation for 10 minutes at $37^{\circ} \mathrm{C}$. For the purpose of control reaction, equal volume of distilled water was added in place of plant extract. Further, $30 \mu \mathrm{L} \mathrm{HCl} \mathrm{(1M)} \mathrm{and} 120 \mu \mathrm{L}$ IKI were added to each well to terminate the reaction after which the absorbance of each well was spectrophotometrically recorded at $630 \mathrm{~nm}$. Entire procedure was repeated in triplicate, and percent inhibition of $\alpha$-amylase activity was calculated using following equation.

$\% \alpha-$ amylase inhibition $=\left(\frac{\mathrm{Abs}_{\text {control }}-\mathrm{Abs}_{\text {sample }}}{\mathrm{Abs}_{\text {control }}}\right) \times 100$

\section{In-silico docking studies}

To predict, the active constituent present in $O$. sanctum that may actually be responsible for the antidiabetic activity possessed by this plant, we screened all the compounds that were previously reported to be present in the plant through in-silico docking studies on insulin receptor protein (PDB: 1IR3) using Molegro Virtual Docker (MVD) software. Threedimensional structure of all the molecular structure was prepared using Marvin sketch software. The crystal structure of insulin receptors was obtained from the protein data bank (www.rcsb.org). Solid surface of insulin receptor protein was created, and five different binding cavities were selected on it. Energies of both ligand and protein were set to minimum and docking process was initiated. Result of the best run was taken as the final observation (having minimum ligand-protein binding energy in $\mathrm{kcal} / \mathrm{mol}$ ), and ligand-receptor interaction image was generated using MVD [28-30].

\section{RESULTS AND DISCUSSION}

Extractive yield and phytochemical screening

Hydroalcoholic Soxhlet extraction of 0 . sanctum resulted in the crude extractive yield of $35.43 \%$. Lyophilized crude extract mainly showed the presence of alkaloids, glycosides, flavonoids, carbohydrates, acidic compounds, and saponins the extract. Tests for volatile oil, proteins, amino acids, and lignin did not show positive results.

\section{Antioxidant activity}

Total phenolic content present in the extract was determined in term of GAE from the standard curve of gallic acid (Fig. 1a). A high correlation $\left(r^{2}=0.9976\right)$ between concentration and corresponding absorbance was observed from the calibration curve of gallic acid which showed linear regression equation of $y=1.0988 x-0.0984$. Total phenolic content in the HEOS was calculated to be $0.366 \mathrm{mg} \mathrm{GAE} / \mathrm{g}$ crude extract. Total flavonoid content of the crude extract was determined in term of QE from the standard curve of quercetin (Fig. 1b). Linear regression equation of $y=0.1174 x+0.0052$ and high degree of correlation $\left(r^{2}=0.9983\right)$ between concentration and corresponding absorbance was observed from the calibration curve. High levels of total flavonoids $(0.113 \mathrm{mg} \mathrm{QE} / \mathrm{g}$ crude extract) were observed to be present in the HEOS. Antioxidant properties possessed by the plant or extract are generally attributed to the presence of total phenolics and flavonoids in it [31].

We demonstrated that HEOS possessed high levels of phenolic and flavonoid compounds, which may be responsible for the high potential of HEOS to scavenger DPPH free radicle. DPPH radical scavenging assay is a well-established assay to determine the antioxidant potential of the herbal extracts with high reliability and accuracy [21]. DPPH assay is based on the spectrophotometric measurement of the absorbance of colored free radical that DPPH forms in the methanolic solution at $517 \mathrm{~nm}$. DPPH is converted to more stable and colorless molecule after it gains electrons from the antioxidant substance. Therefore, stronger the antioxidant potential of plant extract, more discoloration of DPPH solution it will produce; which is recorded spectrophotometrically [21] In the present study, hydroalcoholic extract was subjected to DPPH radicle scavenging assay at different concentrations and radicle scavenging activity was compared to ascorbic acid. Concentration depended scavenging activity was observed for both standard and plant (Fig. 2). Hydroalcoholic extract resulted in $68.71 \pm 2.98 \%$ DPPH radicle scavenging activity at the highest concentration while ascorbic acid demonstrated $98.72 \pm 0.95 \%$ inhibition at the same concentration.

It has now become evident that oxidative stress is primarily involved in the development and progression of diabetic complications and intervention which lower oxidative stress or elevate antioxidant defense enzymes in the body are known to be beneficial during diabetes [32]. In the present study, HEOS demonstrated good potential to scavenge DPPH free radical which can be attributed to the presence of high levels of phenolic and flavonoids in the plant extract. Therefore, $O$. sanctum can prove beneficial in the management of diabetic complications via reducing oxidative stress.

\section{Anti-inflammatory activity}

Proteins possess well-defined and specific functions within the living system which is somewhat guided by the complex structure. In response to several external or internal stressors, proteins may lose their wellorganized structure and thereby render them non-functional. Protein denaturation causes inflammation and several researches depict

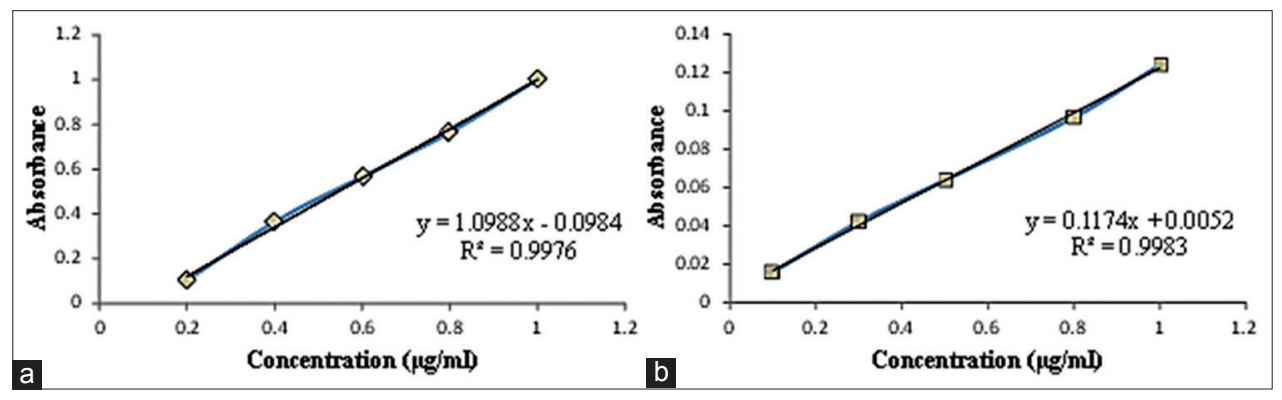

Fig. 1: Standard curve of gallic acid (a) and quercetin (b) 
that non-steroidal anti-inflammatory drugs have exceptional ability to inhibit protein denaturation [31]. On this ground, we evaluated anti-inflammatory potential of HEOS in term of its ability to inhibit denaturation of albumin and results are depicted in Fig. 3a. Inhibition of protein denaturation is the simple and rapid method used to screen synthetic or natural compounds/extract for their anti-inflammatory property [33]. Plant extract showed concentration-dependent prevention of albumin denaturation with maximum inhibition of $82.370 \pm 3.42 \%$ at $1000 \mu \mathrm{g} / \mathrm{ml}$, which was comparable to standard drug, diclofenac sodium $(83.78 \pm 4.34 \%)$.

Cellular membrane initiates an inflammatory response by generating arachidonic acid from membrane phospholipids which generate various inflammatory mediators through cyclooxygenase and lipoxygenase pathway. Therefore, it can be assumed that drugs that are capable of stabilizing cellular membrane will reduce the generation of inflammatory mediators and thus suppress inflammation [34]. RBC membrane resembles lysosomal membrane structurally as well as functionally, and therefore, is used for in-vitro anti-inflammatory assays. Various antiinflammatory drugs are known to exert their anti-inflammatory action by stabilizing lysosome cellular membrane and thereby preventing the release of hydrolytic enzymes which induces inflammation [35]. Results of the HEOS on RBC membrane stabilization were compared to diclofenac sodium and are depicted in Fig. 3b. Consistent dosedependent increase in the membrane stabilization was observed for extract treatment from 250 to $1000 \mu \mathrm{g} / \mathrm{ml}$ concentration. Maximum stabilization of cellular membrane was observed to be $78.28 \pm 6.63 \%$, which was comparable to diclofenac sodium (88.96 \pm 5.44$)$.

These results indicate that HEOS is an efficient anti-inflammatory intervention, and this activity can be attributed to its high potential to prevent denaturation of proteins and stabilizes cellular membrane. During hyperglycemia, inflammatory mediators are generated

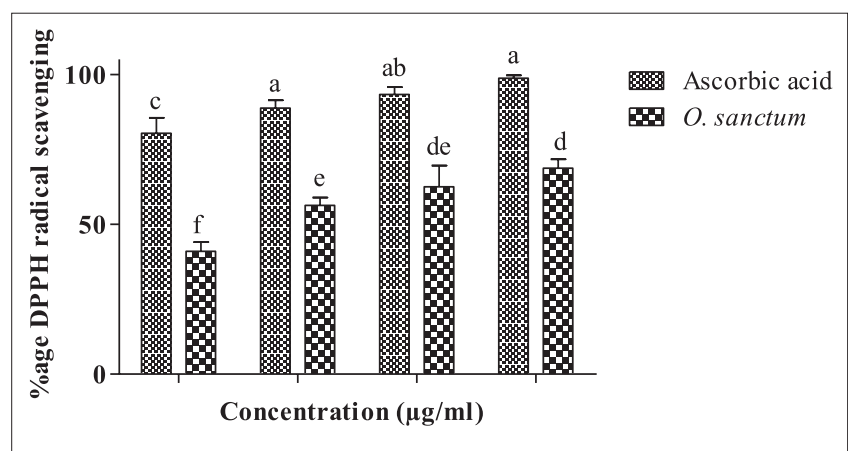

Fig. 2: \% 2,2-diphenyl-1-picrylhydrazyl free radical scavenging activity of the hydroalcoholic extract of Ocimum sanctum. Data are expressed as means \pm standard deviation $(n=3)$. Different letters above the error bar of histograms indicate significant different at $p<0.05$ by Duncan's multiple range test excessively which induce cellular damage and thus contributes in the development and progression of diabetes-mediated complications [36]. Therefore, $O$. sanctum can be beneficial in the management of complications by controlling inflammatory stress during diabetes.

\section{Inhibition of $\alpha$-glucosidase activity}

$\alpha$-Glucosidase is involved in the conversion of unabsorbable dietary polysaccharides into monomer, especially D-glucose, in the gut which is then absorbed from gastrointestinal tract (GIT) and reached blood circulation thereby elevating blood glucose level. Inhibition of this enzyme reduces dietary inflow of glucose and thereby hyperglycemia [37]. In the present study, we screened HEOS for its potential to inhibit $\alpha$-glucosidase activity and results are depicted in Fig. 4. Extract treatment produced concentration-dependent inhibition of $\alpha$-glucosidase activity which was observed to be in the range of $34.17-71.45 \%$. These results were comparable to acarbose, which showed much higher inhibitory activity in the range of 43.06-97.10\%. From these results, it can be concluded that plant extract possesses appreciable potential to inhibit $\alpha$-glucosidase, and therefore, may reduce the dietary inflow of glucose and blood glucose levels during diabetes.

\section{Inhibition of $\alpha$-amylase activity}

$\alpha$-Amylase is another enzyme involved in the digestion of carbohydrates within the GIT. $\alpha$-amylase, along with $\alpha$-glucosidase, reduces blood glucose level by lowering dietary inflow of glucose. Inhibition of $\alpha$-amylase is another quick, well-established, and extensively used in-vitro model to screen antidiabetic drugs. Potential of HEOS to inhibit activity of this enzyme was evaluated and results are depicted in Fig. 5. Unlike $\alpha$-glucosidase inhibition, extract treatment did not show any appreciable inhibition of $\alpha$-amylase. Very low concentrationdependent inhibition was observed in the range of $1.94-14.88 \%$ at the concentration range of $250-1000 \mu \mathrm{g} / \mathrm{ml}$. On the other hand, quercetin, taken as reference compound, appreciably inhibited enzymatic activity $13.51-59.92 \pm 4.78 \%$ at similar concentrations. These results indicate that HEOS is not capable of inhibiting $\alpha$-amylase activity and may not be able to control dietary inflow of glucose through this mechanism.

\section{In-silico docking studies}

Molecular docking is a computational tool used to predict molecules with specific activity by their in-silico interaction with the target protein. Docking outcome provides us with the ligand-protein interaction energy (kcal/mol), number of interactions, and amino acids involved in it, based on which protein specific activity of a compound is predicted $[37,38]$. We screened compounds present in $O$. sanctum against insulin receptor (PDB: 1IR3) using MVD and results are depicted in Table 1. Compounds showing maximum interactions with the receptor and having minimum ligand-receptor binding energy were predicted to be most effective. From our study, rosmarinic acid, stigmasterol, linalool, bieugenol, and aesculin showed the best interaction with 1IR3 in terms of interaction energy, bond length, and number of interactions and were predicted to be most effective molecules. Fig. 6 depicts the images of ligand-protein interaction. These molecules showed exceptionally good interaction

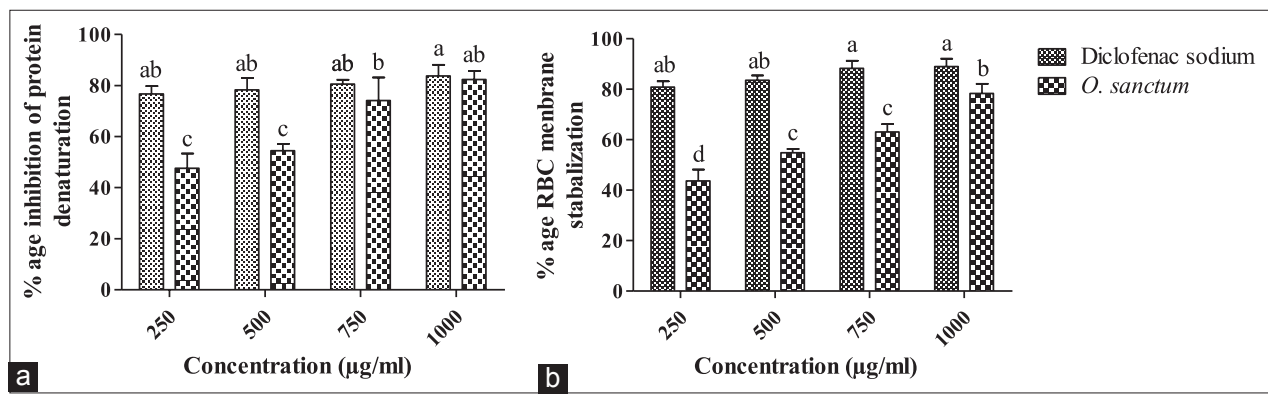

Fig. 3: \% inhibition of protein denaturation (a) and \% red blood cell membrane stabilization (b) activity of hydroalcoholic extract of Ocimum sanctum. Data are expressed as means \pm standard deviation $(n=3)$. Different letters above the error bar of histograms indicate significant different at $\mathbf{p}<0.05$ by Duncan's multiple range test 
Table 1: Docking interaction of different compounds present in 0 . sanctum with insulin receptor (PDB: 1IR3)

\begin{tabular}{llll}
\hline S. No. & $\begin{array}{l}\text { Name of compound } \\
\text { (energy in kcal/mol) }\end{array}$ & $\begin{array}{l}\text { Molecular dock score } \\
\text { (kcal/mol) }\end{array}$ & $\begin{array}{l}\text { Number of interactions } \\
\text { with protein }\end{array}$ \\
\hline 1 & Quercetin $(54.28 \mathrm{kcal} / \mathrm{mol})$ & -125.112 & 12 \\
2 & Rosmarinic acid $(48.7 \mathrm{kcal} / \mathrm{mol})$ & -119.174 & 7 \\
3 & Linalool $(29.09 \mathrm{kcal} / \mathrm{mol})$ & -119.022 & 4 \\
4 & Bieugenol $(63.72 \mathrm{kcal} / \mathrm{mol})$ & -115.687 & 11 \\
5 & Aesculin $(44.28 \mathrm{kcal} / \mathrm{mol})$ & \\
\hline
\end{tabular}

O. sanctum: Ocimum sanctum, PDB: Protein data bank

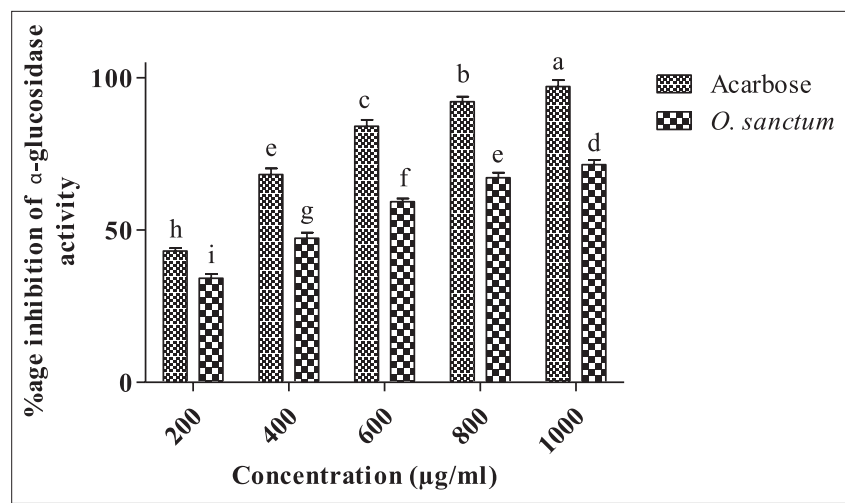

Fig. 4: \% inhibition of the $\alpha$-glucosidase enzymatic activity by the hydroalcoholic extract of Ocimum sanctum. Data are expressed as means \pm standard deviation $(n=3)$. Different letters above the error bar of histograms indicate significant different at $p<0.05$ by Duncan's multiple range test

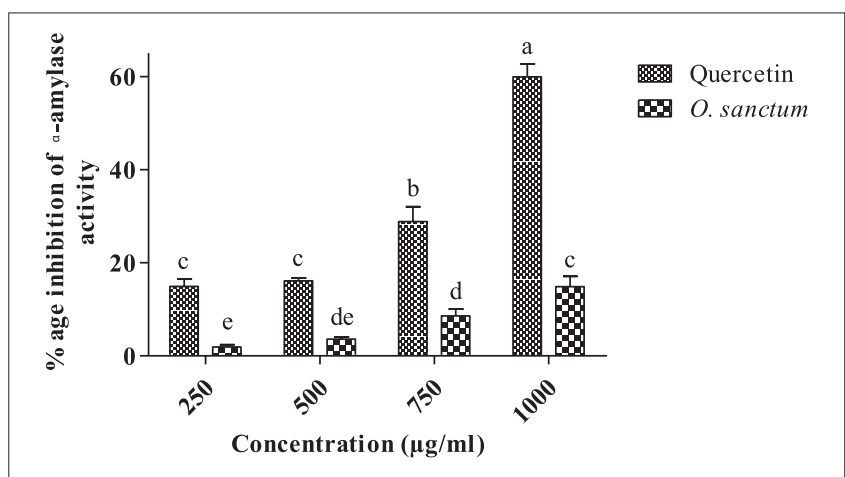

Fig. 5: \% inhibition of the $\alpha$-amylase enzymatic activity by the hydroalcoholic extract of Ocimum sanctum. Data are expressed as means \pm standard deviation $(n=3)$. Different letters above the error bar of histograms indicate significant different at $p<0.05$ by Duncan's multiple range test

with 1IR3 protein and can be considered as potential molecules that may prove to be beneficial in diabetes through their direct action on insulin receptor. However, these molecules need to be further screened extensively through in-vitro and in-vivo experimentation before reaching any decisive conclusion.

\section{CONCLUSION}

Present findings provide an experimental justification to the traditional use of this plant for the management of hyperglycemia and provide preliminary insite into the possible mechanisms through which O. sanctum may aid to overcome diabetes and associated complications. Plant extract exhibited good antioxidant and anti-inflammatory properties which may result in preventing diabetic complications that are generally attributed to excessive oxidative and inflammatory stress during hyperglycemia. Further antidiabetic effect of 0 . sanctum may

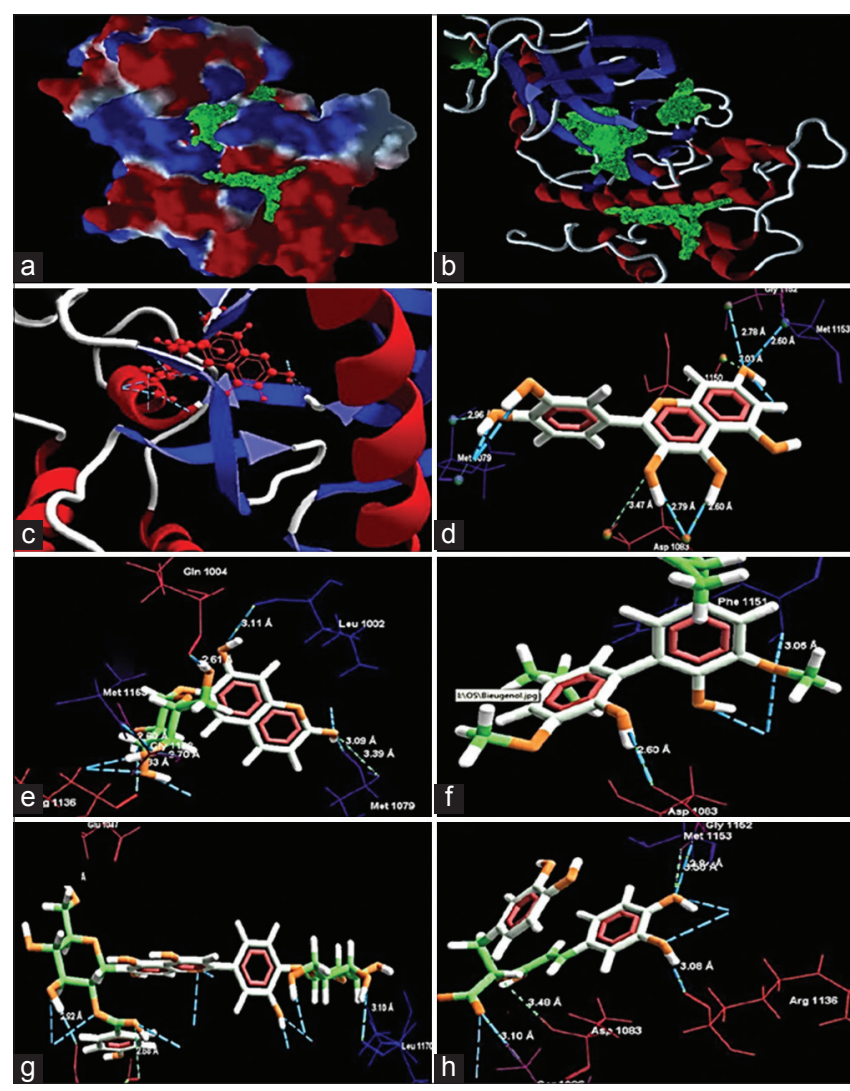

Fig. 6: Docking interaction of different constituents of Ocimum sanctum on active site of 1IR3 Protein Data Bank (PDB).

(a) Protein surface; (b) secondary structure of 1IR3 protein;

(c) secondary protein structure with interacting molecule;

(d-h) depicts interaction of quercetin, rosmarinic acid, linalool, bieugenol, and aesculin with 1IR3 PDB, respectively

be attributed to its strong inhibitory effect on $\alpha$-glucosidase enzyme and presence of rosmarinic acid, stigmasterol, linalool, bieugenol, and aesculin, which were predicted to be potentially antidiabetic moieties of this plant.

\section{ACKNOWLEDGMENTS}

Authors would like to acknowledge the Jaypee University of Information Technology, for providing facilities to do this work.

\section{REFERENCES}

1. International Diabetes Federation. The Diabetes Atlas. $7^{\text {th }}$ ed. Brussels: International Diabetes Federation; 2015

2. Cade WT. Diabetes-related microvascular and macrovascular diseases in the physical therapy setting. Phys Ther 2008;88(11):1322-35.

3. Mehta V, Malairaman U. Flavonoids: Prospective strategy for the management of diabetes and its associated complications. In: Wang V editor. Handbook of Research on Advancing Health Education through Technology. Pennsylvania: IGI Global; 2006. p. 286-328. 
4. Kolb H, Mandrup-Poulsen T. The global diabetes epidemic as a consequence of lifestyle-induced low-grade inflammation. Diabetologia 2010;53(1):10-20.

5. Bondia-Pons I, Ryan L, Martinez JA. Oxidative stress and inflammation interactions in human obesity. J Physiol Biochem 2012;68(4):701-11.

6. Winter WE, Signorino MR. Diabetes Mellitus: Pathophysiology, Etiologies, Complications, Management, and Laboratory Evaluation: Special Topics in Diagnostic Testing. Washington: American Association for Clinical Chemistry Press; 2002.

7. Gordon MC, David JN. Natural product drug discovery in the next millennium. Pharm Boil 2001;39:8-17.

8. Prakash P, Gupta N. Therapeutic uses of Ocimum sanctum Linn (Tulsi) with a note on eugenol and its pharmacological actions: A short review. Indian J Physiol Pharmacol 2005;49(2):125-31.

9. Modak M, Dixit P, Londhe J, Ghaskadbi S, Devasagayam TP. Indian herbs and herbal drugs used for the treatment of diabetes. J Clin Biochem Nutr 2007;40(3):163-73

10. Patil RN, Patil RY, Ahirwar B, Ahirwar D. Evaluation of antidiabetic and related actions of some Indian medicinal plants in diabetic rats. Asian Pac J Trop Med 2011;4(1):20-3.

11. Chattopadhyay RR. A comparative evaluation of some blood sugar lowering agents of plant origin. J Ethnopharmacol 1999;67(3):367-72.

12. Hussain EH, Jamil K, Rao M. Hypoglycaemic, hypolipidemic and antioxidant properties of tulsi (Ocimum sanctum linn) on streptozotocin induced diabetes in rats. Indian J Clin Biochem 2001;16(2):190-4.

13. Sethi J, Sood S, Seth S, Talwar A. Evaluation of hypoglycemic and antioxidant effect of Ocimum sanctum. Indian $\mathrm{J}$ Clin Biochem 2004;19(2):152-5

14. Gupta S, Mediratta PK, Singh S, Sharma KK, Shukla R. Antidiabetic, antihypercholesterolaemic and antioxidant effect of Ocimum sanctum (Linn) seed oil. Indian J Exp Biol 2006;44(4):300-4

15. Hannan JM, Marenah L, Ali L, Rokeya B, Flatt PR, Abdel-Wahab YH Ocimum sanctum leaf extracts stimulate insulin secretion from perfused pancreas, isolated islets and clonal pancreatic beta-cells. J Endocrinol 2006;189(1):127-36.

16. Husain I, Chander R, Saxena JK, Mahdi AA, Mahdi F. Antidyslipidemic effect of Ocimum sanctum leaf extract in streptozotocin induced diabetic rats. Indian J Clin Biochem 2015;30(1):72-7.

17. Halim EM, Mukhopadhyay AK. Effect of Ocimum sanctum (Tulsi) and vitamin $\mathrm{E}$ on biochemical parameters and retinopathy in streptozotocin induced diabetic rats. Indian J Clin Biochem 2006;21(2):181-8.

18. Khandelwal KR. Practical Pharmacognosy: Techniques and Experiments. $17^{\text {th }}$ ed. Pune: Nirali Prakashan; 2007.

19. Singleton VL, Rossi JA. Colorimetry of total phenolics with phosphomolybdic-phosphotungstic acid reagents. Am J Enol Vitic 1965;16(3):144-58.

20. Zhishen J, Mengcheng T, Jianming W. The determination of flavonoid contents in mulberry and their scavenging effects on superoxide radicals. Food Chem 1999;64:555-9.

21. Sharma OP, Bhat TK. DPPH antioxidant assay revisited. Food Chem 2009; $113: 1202-5$

22. Ullah HM, Zaman S, Juhara F, Akter L, Tareq SM, Masum EH, et al. Evaluation of antinociceptive, in-vivo \& in-vitro anti-inflammatory activity of ethanolic extract of Curcuma zedoaria rhizome. BMC Complement Altern Med 2014;14:346.
23. Asanuma M, Taguchi C, Kumagi T, Uesaka H, Hosokawa H, Kuriya SI. The hydrogen ion concentration $(\mathrm{pH})$ in blood samples with K-2EDTA and K-3EDTA affects mean corpuscular volume values in hemodialysis patients. Lab Hematol 2000;6:67-72.

24. Sadique J, Al-Rqobah W, Bughaith M, El-Gindy A. The bio-activity of certain medicinal plants on the stabilization of RBC membrane system. Fitoterapia 1989;60:525-32

25. Shinde UA, Phadke AS, Nair AM, Mungantiwar AA, Dikshit VJ Saraf MN. Membrane stabilizing activity-a possible mechanism of action for the anti-inflammatory activity of Cedrus deodara wood oil. Fitoterapia 1999;70(3):251-7.

26. Elya B, Basah K, Mun'im A, Yuliastuti W, Bangun A, Septiana EK Antidiabetic activity test by inhibition of $\alpha$-glucosidase and phytochemical screening from the most active fraction of Bun (Antidesma bunius L.) stem barks and leaves. J Biomed Biotechno 2011;2012:281078

27. Zengin G, Uysal A, Gunes E, Aktumsek A. Survey of phytochemical composition and biological effects of three extracts from a wild plant (Cotoneaster nummularia Fisch. et Mey.): A potential source for functional food ingredients and drug formulations. PLoS One 2014;9(11):e113527.

28. Halgern TA. A new prospective in the docking analysis. Comput Chem 1990;20:720-7.

29. Hasel WH, Hendrickson TF, Still WC. A rapid approximation to the solvent accessible surface areas of atoms. Tetrahedron Comput Methodol 1988;1:103-16.

30. Jayaram B, Sprous D, Beveridge DL. Solvation free energy of biomacromolecules: Parameters for a modified generalized born model consistent with the AMBER force field. J Phys Chem 1998;B102:9571-6.

31. Saso L, Valentini G, Casini ML, Grippa E, Gatto MT, Leone MG, et al. Inhibition of heat-induced denaturation of albumin by nonsteroidal antiinflammatory drugs (NSAIDs): Pharmacological implications. Arch Pharmacal Res 2001;24(2):150-8.

32. Shahidi F, Wanasundara PK. Phenolic antioxidants. Crit Rev Food Sci Nutr 1992;32(1):67-103.

33. Ceriello A, Motz E. Is oxidative stress the pathogenic mechanism underlying insulin resistance, diabetes, and cardiovascular disease? The common soil hypothesis revisited. Arterioscler Thromb Vasc Biol 2004;24(5):816-23

34. Tripathi KD. Essentials of medical pharmacology. $7^{\text {th }}$ ed. New Delhi: JP Medical Ltd; 2013.

35. Anosike CA, Obidoa O, Ezeanyika LU. Membrane stabilization as a mechanism of the anti-inflammatory activity of methanol extract of garden egg (Solanum aethiopicum). Daru J Pharm Sci 2012;20(1):76.

36. Forbes JM, Coughlan MT, Cooper ME. Oxidative stress as a major culprit in kidney disease in diabetes. Diabetes 2008;57(6):1446-54

37. Vangrevelinghe E, Zimmermann K, Schoepfer J, Portmann R, Fabbro D, Furet P. Discovery of a potent and selective protein kinase CK2 inhibitor by high-throughput docking. J Med Chem 2003;46(13):2656-62

38. Rollinger JM, Steindl TM, Schuster D, Kirchmair J, Anrain K, Ellmerer EP, et al. Structure-based virtual screening for the discovery of natural inhibitors for human rhinovirus coat protein. J Med Chem 2008;51(4):842-51 